\title{
TRAJECTORY SENSITIVITY TO RAWINSONDE DATA RESOLUTION
}

\author{
Jonathan D. Kahl* and Perry J. Samson \\ Department of Atmospheric and Oceanic Science, Space Physics Research Laboratory, University of \\ Michigan, Ann Arbor, MI 48109, U.S.A.
}

(First received 11 September 1987 and in final form 14 January 1988)

\begin{abstract}
Meteorological measurements collected during the Cross Appalachian Tracer Experiment (CAPTEX) were used to evaluate the sensitivity of trajectory calculations to variations in the spatial and temporal density of rawinsonde data. Data resolution was systematically adjusted in order to separately evaluate the effects of enhanced spatial and temporal resolution. Variable mixed layer, constant layer, and constant level trajectories were more sensitive to increases in spatial resolution than to increases in temporal resolution. For mixed layer, 0-400-m layer and 400-m level trajectories, sensitivity to combined increases in both spatial and temporal rawinsonde data resolution was dominated by the effects of spatial resolution alone. This dominance was not observed for trajectories calculated at higher levels and layers.

Trajectory case studies corresponding to two CAPTEX tracer releases were presented. These examples illustrate the potential effects of a single additional measurement at an existing National Weather Service rawinsonde station, and the importance of specifying the initial transport wind accurately.
\end{abstract}

Key word index: Trajectory sensitivity, spatial and temporal data resolution, rawinsonde.

\section{INTRODUCTION}

Trajectory analysis is commonly used as a diagnostic tool for assessing the long-range transport of atmospheric pollutants. A wide range of numerical techniques are available, with major differences in input data requirements and transport assumptions (e.g. isobaric, isentropic, mixed layer, isosigma). Some trajectory techniques can be computationally demanding (Warner et al., 1983), while others are more affordable for long-term pollution studies (Heffter, 1980).

The latter class of trajectory models use rawinsonde measurements to define the transport wind. These measurements are available twice-daily at locations separated by approx. $400 \mathrm{~km}$. Interpolation between rawinsonde stations and measurement times produce erroneous wind fields (Kahl and Samson, 1986). Thus trajectory calculations are sensitive to the spatial density and temporal frequency of rawinsonde observations.

The limited availability of fine-scale rawinsonde data has prevented detailed investigations of trajectory sensitivity to data resolution. Nevertheless, studies of trajectory accuracy have provided insight on trajectory sensitivity. Clarke et al. (1983) modeled mixed layer trajectories based on both 6- and 12-h rawinsonde data. Trajectory accuracy, as defined by the model's ability to reproduce observed tetroon transport, increased only slightly with increased tem-

* Present address: Geophysical Monitoring for Climatic Change, Air Resources Laboratory, National Oceanic and Atmospheric Administration, 325 Broadway, Boulder, CO 80303, U.S.A. poral data resolution. The sample size ( 26 trajectories) was insufficient to draw any quantitative conclusions, however. Walmsley and Mailhot (1983) compared trajectory calculations with numerical solutions based on an analytical non-divergent wind. They found spatial interpolation of the wind field to be the largest source of error. An analytical study by Kuo et al. (1985) examined the accuracy of isentropic trajectory calculations based on a 72-h model simulation of an evolving synoptic cyclone. Varying degrees of spatial and temporal data resolution were constructed by systematically degrading the complete model database, upon which the 'true' trajectories were built. Contrary to Walmsley and Mailhot's findings, they found temporal interpolation to be a larger source of error than spatial interpolation. Finally, in a previous paper (Kahl and Samson, 1986) we developed a 'trajectory of errors' technique in which observed distributions of spatial and temporal wind interpolation errors were used to obtain probabilistic estimates of trajectory errors. Like Walmsley and Mailhot, we concluded that spatial interpolation was the largest source of trajectory errors. The difference in conclusions is largely due to differences in the meteorological situations that were studied.

The dissimilar research methodologies in the studies cited above reflect the difficulty in obtaining 'true' trajectories with which to evaluate errors. While our earlier work (Kahl and Samson, 1986) provided estimates of trajectory accuracy based on wind interpolation errors, this paper examines trajectory sensitivity without specifically addressing accuracy. Using rawinsonde data collected during the Cross 
Appalachian Tracer Experiment, we performed sensitivity experiments similar to those of Clarke et al. In the present study, however, rawinsonde data resolution was systematically adjusted in order to separately evaluate the effects of variations in spatial and temporal data density. In addition, two case studies are presented which exemplify the effects of data resolution on mixed layer trajectory calculations.

\section{RAWINSONDE DATA BASE}

The Cross Appalachian Tracer Experiment (CAPTEX) was conducted in eastern North America during September and October 1983 (Ferber et al., 1986). The purpose of the experiment was to gather empirical data on the long-range atmospheric transport and dispersion of a passive gaseous tracer. Seven releases of perfluoro-monomethyl-cyclohexane $\left(\mathrm{C}_{7} \mathrm{~F}_{14}\right)$, a non-reactive, non-depositing perfluorocarbon tracer (five from Dayton, $\mathrm{OH}$; two from Sudbury, Ontario) were made during generally persistent flow conditions with little precipitation. Seven U.S. National Weather Service (NWS) rawinsonde stations and one Canadian station located within the experimental area increased the frequency of their soundings to four times per day whenever tracer material was present. In addition, 12 supplemental stations, including one at each tracer release site, were established to enhance the spatial resolution of the rawinsonde data base. The locations of the rawinsonde stations are shown in Fig. 1.

\section{METHODOLOGY}

Forward trajectories were calculated using the ARLATAD model (Heffter, 1980). A variety of transport levels and layers were utilized including the mixed layer, which extends from the surface to the first critical inversion based above $300 \mathrm{~m}$ above ground level. A critical inversion was defined (Heffter, 1980) as a layer in which (a) the potential temperature lapse rate was $>5 \mathrm{~K} \mathrm{~km}^{-1}$, and (b) the potential temperature difference between the top and bottom of the layer was $\geqslant 2 \mathrm{~K}$.

Trajectories originated at five locations including the tracer release sites. These locations are shown in Fig. 1 and listed in Table 1 along with the transport levels and layers used. Trajectories were calculated for all periods during which rawinsonde data of increased spatial and temporal resolution were available consecutively for $24 \mathrm{~h}$. The start times for the 32 periods utilized are listed in Table 2 . These periods include the CAPTEX tracer experiments.

For each level and layer, a reference set of trajectories was first prepared using only the routinely available, twice daily (0000 and 1200 UT) rawinsonde database. This database will be referred to as 'NWS', although reports from two Canadian stations were included. The reference database was then separately augmented with:

(1) 0600 and 1800 UT NWS soundings,

(2) 0000 and 1200 UT supplemental soundings, and

(3) 0600 and 1800 UT NWS soundings and all supplemental soundings.

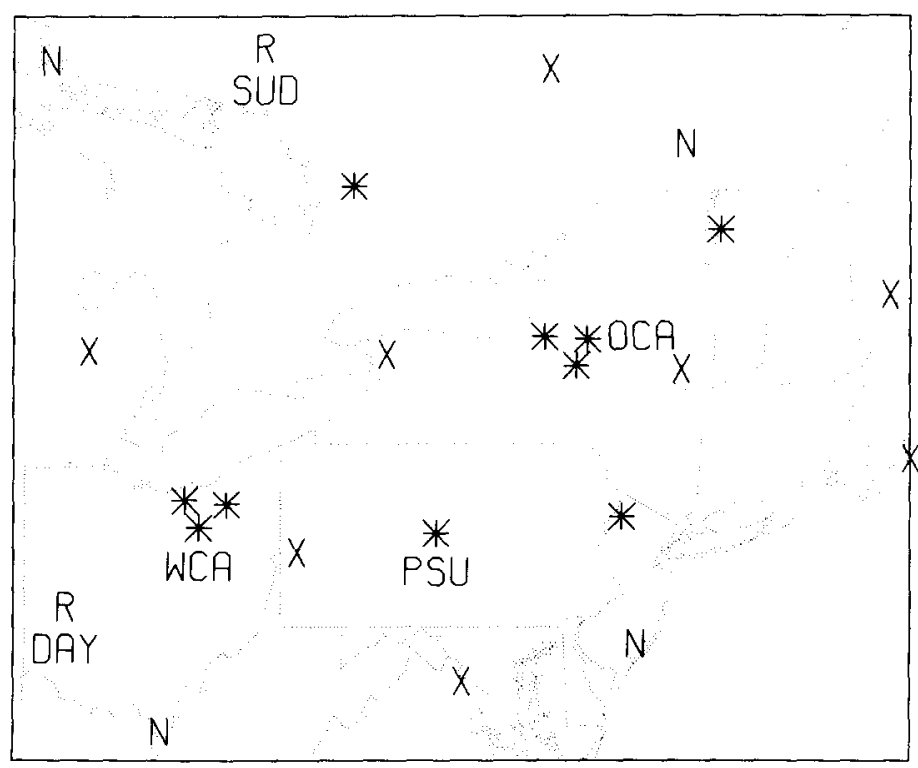

Fig. 1. Locations of the rawinsonde stations in the CAPTEX experimental area. Participating NWS and Canadian stations are indicated by ' $X$ ', supplemental stations by asterisk, and release site stations by ' $R$ '. The symbol ' $N$ ' indicates NWS and Canadian stations that did not increase the temporal frequency of their measurements. Trajectory origins are identified by threeletter abbreviations 
Table 1. Description of trajectory origins and transport levels and layers utilized. Heights are in units of $m$ above ground level

\begin{tabular}{|c|c|c|c|}
\hline & Abbrev. & Latitude $(\mathrm{N})$ & Longitude (W) \\
\hline \multicolumn{4}{|l|}{ Trajectory origins: } \\
\hline \multicolumn{4}{|l|}{ Location } \\
\hline Dayton, $\mathrm{OH}$ & DAY & $39^{\circ} 54^{\prime}$ & $84^{\circ} 13^{\prime}$ \\
\hline Sudbury, Ontario & SUD & $46^{\circ} 37^{\prime}$ & $80^{\circ} 47^{\prime}$ \\
\hline Wayne County Airport, $\mathrm{OH}$ & WCA & $40^{\circ} 52^{\prime}$ & $81^{\circ} 53^{\prime}$ \\
\hline Pennsylvania State University & PSU & $40^{\circ} 48^{\prime}$ & $77^{\circ} 54^{\prime}$ \\
\hline Oneida County Airport, NY & $\mathrm{OCA}$ & $43^{\circ} 09^{\prime}$ & $75^{\circ} 22^{\prime}$ \\
\hline \multicolumn{4}{|l|}{ Transport levels and layers: } \\
\hline Fixed levels & $\begin{array}{c}400 \mathrm{~m} \\
800 \mathrm{~m} \\
1200 \mathrm{~m} \\
1600 \mathrm{~m}\end{array}$ & & \\
\hline Fixed layers & $\begin{array}{l}-400 \mathrm{~m} \\
-800 \mathrm{~m} \\
-1200 \mathrm{~m} \\
-1600 \mathrm{~m}\end{array}$ & & \\
\hline Variable layer & layer & & \\
\hline
\end{tabular}

Table 2. Origin times (UT) for trajectory calculations. Times corresponding to the case studies are in italics

\begin{tabular}{|c|c|c|c|}
\hline Month (1983) & Day & Hour & \\
\hline September & $\begin{array}{l}18 \\
19 \\
25 \\
26 \\
27\end{array}$ & $\begin{array}{l}1200,1800 \\
0000,0600,1200 \\
1200,1800 \\
0000,0600,1200,1800 \\
0000\end{array}$ & Release no. 1 \\
\hline October & $\begin{array}{r}2 \\
3 \\
4 \\
14 \\
15 \\
25 \\
26 \\
28 \\
29\end{array}$ & $\begin{array}{l}1200,1800 \\
0000,0600,1200,1800 \\
0000 \\
1200,1800 \\
0000 \\
1200,1800 \\
0000,0600,1200 \\
1200,1800 \\
0000,0600,1200\end{array}$ & Release no. 5 \\
\hline
\end{tabular}

The modified databases represent improvements, respectively, in (1) temporal, (2) spatial and (3) spatial and temporal resolution. Trajectories calculated using the modified databases were compared with the reference trajectories to determine differences in horizontal displacement at each 3-h time-step. A total of 160 trajectories were calculated for each level or layer and each set of input data.

Individual displacement differences were calculated according to

$$
d=c\left[(\Delta \phi)^{2}+(\Delta \lambda)^{2} \cos ^{2} \bar{\phi}\right]^{1 / 2},
$$

where $\Delta \phi$ and $\Delta \lambda$ are differences in latitude and longitude, respectively, between the modified and reference trajectory endpoints, $\bar{\phi}=0.5[\phi$ (reference) $+\phi$ (modified) $]$ is the mean latitude, and $c=111.1$, the ratio of $\mathrm{km}$ to degrees latitude. The growth of mean horizontal displacement differences, or sensitivity, due to increases in temporal, spatial, and spatial and temporal resolution was examined as a function of travel time.

\section{RESULTS AND DISCUSSION}

\section{Mixed layer trajectories}

Figure 2 shows results of the sensitivity analysis for mixed layer trajectories. Each line plotted is the mean horizontal difference, as a function of travel time, between the trajectory segment location computed with one version of the modified database and that computed with the reference database. The line labeled ' $\uparrow$ spatial', for example, represents the sensitivity to increased spatial resolution of rawinsonde data. Note that the mean horizontal differences indicate sensitivity and not errors, as none of the trajectories necessarily represent 'truth'. The mean sensitivity $24 \mathrm{~h}$ downwind due to increased spatial resolution 


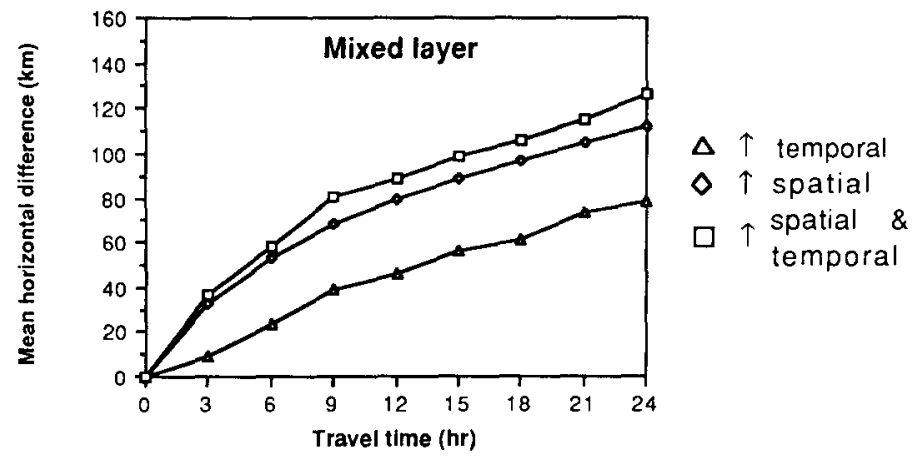

Fig. 2. Sensitivity of estimated mixed layer trajectories to increases in spatial and temporal rawinsonde data resolution.

was $112 \mathrm{~km}$, while that due to increased temporal resolution was $79 \mathrm{~km}$. For the combined increase of both spatial and temporal resolution the mean sensitivity was $126 \mathrm{~km}$, only $13 \%$ greater than the mean for increased spatial resolution.

A quantitative evaluation of the horizontal displacement differences, or sensitivity, was performed using nonparametric statistical techniques. Although the distributions at each time-step were approximately log-normal, the Student's $t$-test could not be used because some of the distributions had unequal variances. Consequently, the Mann-Whitney $U$-test was performed to determine whether differences between the displacement difference distributions were significant at the 0.05 level. The test indicated that differences in sensitivity due to increases in (1) temporal vs spatial resolution and (2) temporal vs spatial and temporal resolution were significant, while differences due to increased spatial vs increased spatial and temporal resolution were not.

This experiment revealed that during relatively quiescent meteorological conditions such as those which occurred during CAPTEX, mixed layer trajectories were more sensitive to increases in spatial resolution of rawinsonde observations than to increases in temporal resolution. Sensitivity to spatial resolution tended to saturate the process so that further sensitivity due to increases in both spatial and temporal resolution was not significant.

\section{Constant layer trajectories}

Results of the sensitivity analyses for constant layer trajectories are shown in Fig. 3. The range of sensitivity to increased temporal resolution, for all layers, was $59-79 \mathrm{~km}$ after $24 \mathrm{~h}$ travel. Sensitivity to spatial resolution, on the other hand, was much greater in the 0-400-m layer (Fig. 3a). After $24 \mathrm{~h}$ travel the mean horizontal difference was $150 \mathrm{~km}$. For the other layers this value was $107 \mathrm{~km}(400-800 \mathrm{~m}$; Fig. $3 \mathrm{~b}) .93 \mathrm{~km}$ $(800-1200 \mathrm{~m}$; Fig. 3c) and $85 \mathrm{~km}(1200-1600 \mathrm{~m}$; Fig. 3d). Trajectories for all layers were more sensitive to spatial resolution than to temporal resolution, particularly in the lowest layer. The sensitivity to increases in both spatial and temporal resolution was only $10-17 \%$ larger than the sensitivity to increased spatial resolution alone.

The large sensitivity to spatial resolution in the 0-400-m layer is presumably due to wind shear effects. Vertical wind shear is nearly always present in this layer due to the frictional influence of the ground. The horizontal shear which often accompanies vertical shear reduces the correlation between winds measured at adjacent rawinsonde stations. An analysis by Kahl and Samson (1986) suggested that elevated shear may increase spatial interpolation errors. No relationship was found between wind shear and temporal interpolation, however.

As observed for mixed layer trajectories, sensitivity to $0-400-\mathrm{m}$ trajectories was dominated by increases in spatial resolution. Sensitivity to increased spatial resolution was significantly greater than sensitivity to increased temporal resolution at the 0.05 level. Sensitivity to increases in both spatial and temporal resolution, however, was not significantly different from that due to increased spatial resolution alone. For the other levels, however, differences between all three sensitivity distributions were significant. Thus, for all layers the sensitivity to increased spatial resolution was significantly greater than that due to increased temporal resolution. For all layers except the $0-400-\mathrm{m}$ layer, the sensitivity to increased spatial and temporal resolution was significantly greater than the sensitivity to increased spatial resolution alone.

\section{Constant level trajectories}

Results of the sensitivity analyses for constant level trajectories are shown in Fig. 4. The wide range in sensitivity observed in the constant layer analyses did not occur for the constant level analyses, suggesting that much of the sensitivity in the lowest layer was due to spatial variability in the wind field below $400 \mathrm{~m}$. As with the variable and constant layer trajectories, the mean differences due to increased spatial resolution were greater than those due to increased temporal resolution. The differences after $24 \mathrm{~h}$ due to increased spatial resolution at the $400-\mathrm{m}$ (Fig. 4a), $800-\mathrm{m}$ (Fig. 4b), 1200-m (Fig. 4c) and 1600-m (Fig. 4d) levels were $110,96,94$ and $84 \mathrm{~km}$, respectively. Correspon- 


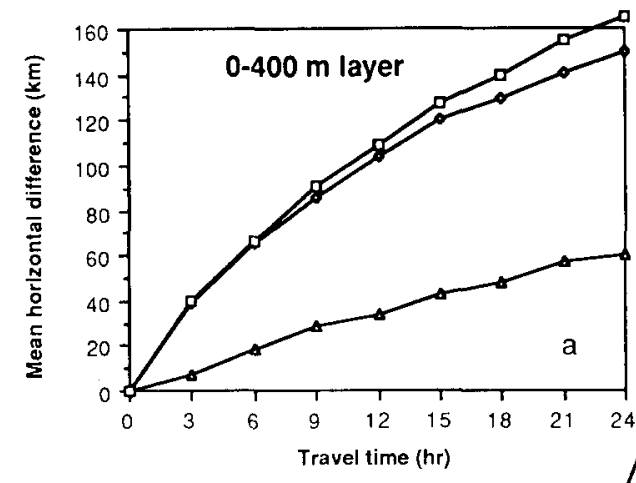

$$
\begin{gathered}
\Delta \uparrow_{\text {temporal }} \\
\diamond \uparrow_{\text {spatial }} \\
\square \uparrow \begin{array}{c}
\text { spatial \& } \\
\text { temporal }
\end{array}
\end{gathered}
$$
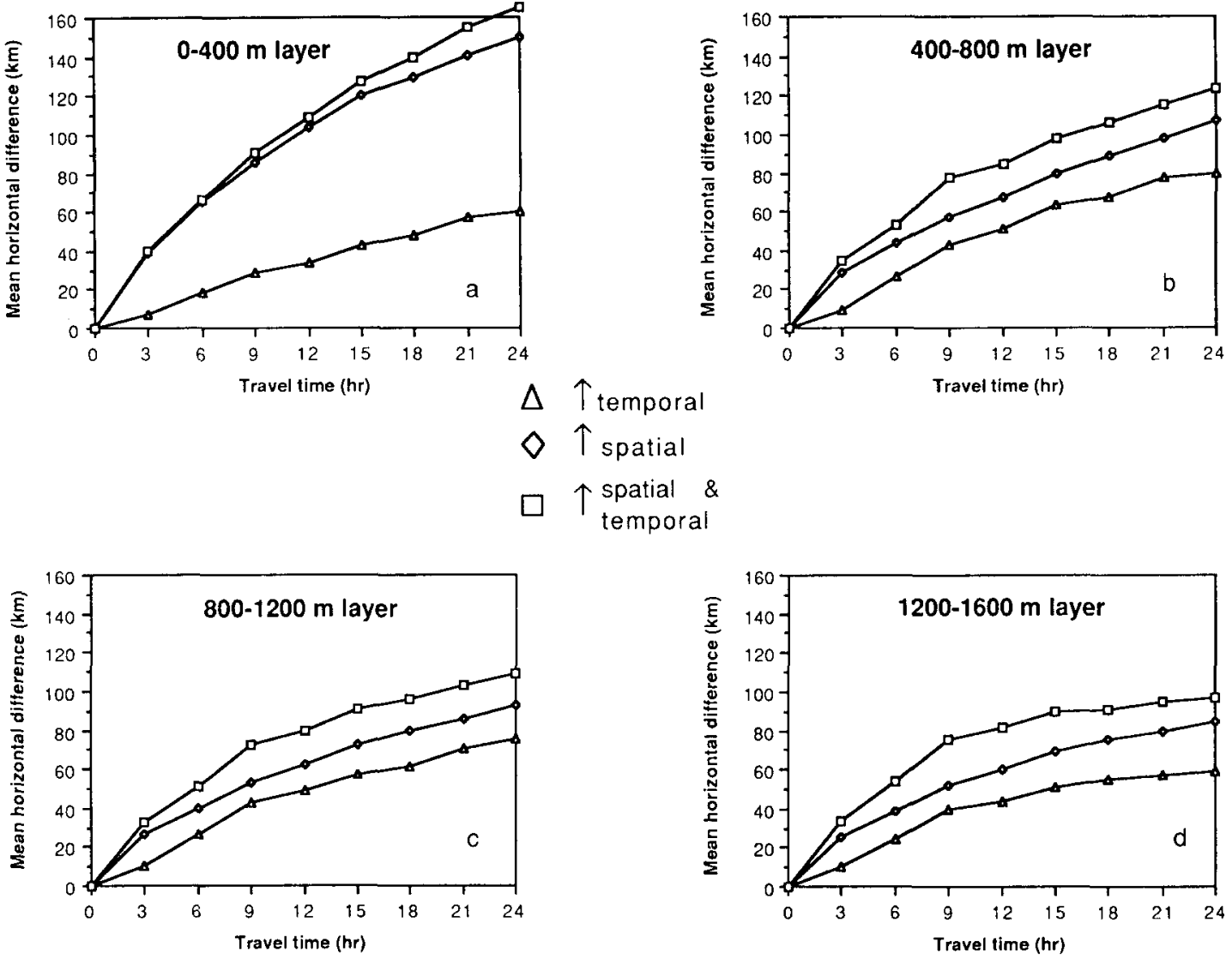

Fig. 3. Sensitivity of estimated constant layer trajectories to increases in spatial and temporal rawinsonde data resolution. Heights above ground level: (a) 0-400 m, (b) $400-800 \mathrm{~m}$, (c) $800-1200 \mathrm{~m}$, (d) $1200-1600 \mathrm{~m}$.

ding differences due to increased temporal resolution were $81,92,65$ and $67 \mathrm{~km}$. Mean differences due to the combined increase of both spatial and temporal resolution were $15-23 \%$ greater than differences due to increased spatial resolution alone.

The sensitivity in the lowest $(400-\mathrm{m})$ level again was saturated by increased spatial resolution, as further sensitivity due to increased spatial and temporal resolution failed to demonstrate statistical significance. For the other levels the differences between all three sensitivity distributions were significant. The only exception was the $800-\mathrm{m}$ level (Fig. 4b), for which the differences in sensitivity to increased temporal vs increased spatial resolution were small.

\section{CASE STUdies}

In order to illustrate the effects of rawinsonde data resolution on trajectory calculations, we have plotted mixed layer trajectories corresponding to two CAPTEX tracer experiments. The cases presented here are examples of heightened sensitivity to temporal (case 1) and spatial (case 2) data resolution. For each case, a brief description of the meteorological conditions is provided.

\section{Case 1: CAPTEX release no. 1}

The first CAPTEX tracer experiment, a Dayton, OH release, was conducted from 1700 to 2000 UT on 18 September 1983 . The sea-level pressure analysis for $1200 \mathrm{UT}$ on 19 September, $14 \mathrm{~h}$ after the release terminated, is shown in Fig. 5. A deep low-pressure center was located over Hudson Bay, with a cold front extending into the CAPTEX area and a warm front over New England. Very little precipitation was associated with this system. A strong high-pressure center was located off the coast of North Carolina. The surface winds in the CAPTEX area were southsouthwest during the $24 \mathrm{~h}$ following the tracer release, while the upper level winds were southwest-west. The surface wind pattern was typical of flow around the back side of a high-pressure system in the northeast U.S.

Figure 6 shows mixed layer trajectories originating at $1800 \mathrm{UT}$ on 18 September, $1 \mathrm{~h}$ into the 3 -h tracer release. The legend 'NWS $12 \mathrm{HR}$ ' denotes the trajectory based on the normally available, twice-daily NWS data (the reference database described earlier). Legends 'NWS 6HR' and 'SUPP 12HR' refer to increased temporal and spatial resolution, respectively, and 'SUPP 6HR' indicates increased spatial and 

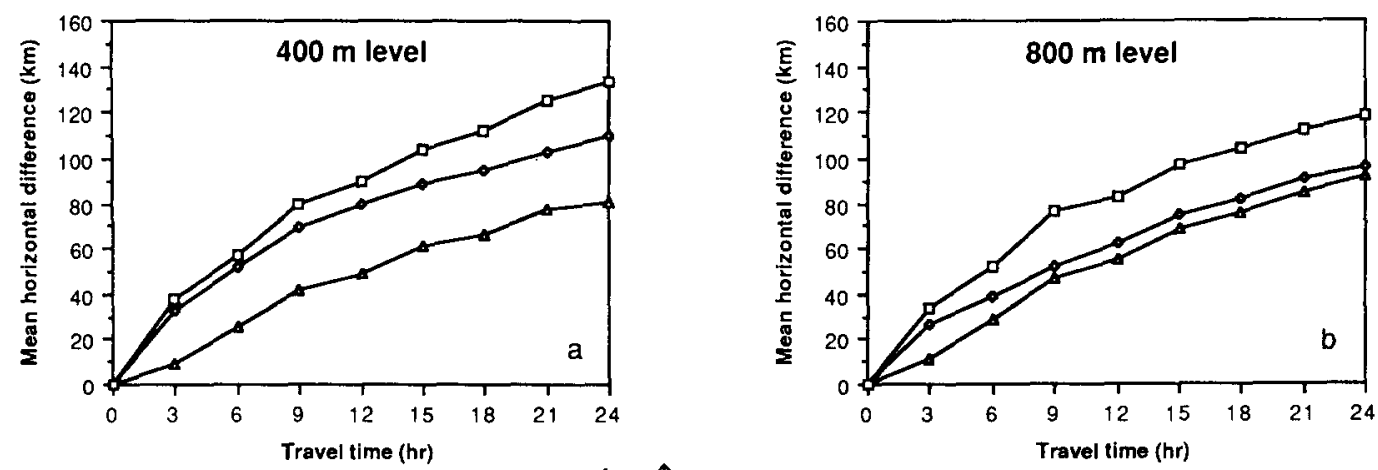

$\Delta \uparrow$ temporal

$\diamond \uparrow$ spatial

$\uparrow$ spatial \&
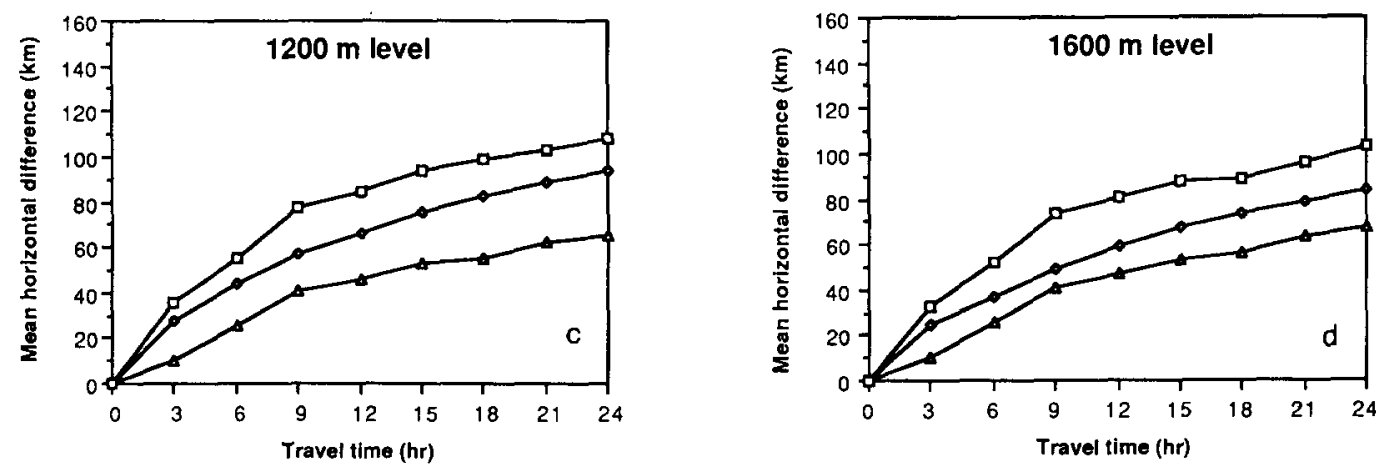

Fig. 4. Sensitivity of estimated constant level trajectories to increases in spatial and temporal rawinsonde data resolution. Heights above ground level: (a) $400 \mathrm{~m}$, (b) $800 \mathrm{~m}$, (c) $1200 \mathrm{~m}$, (d) $1600 \mathrm{~m}$.

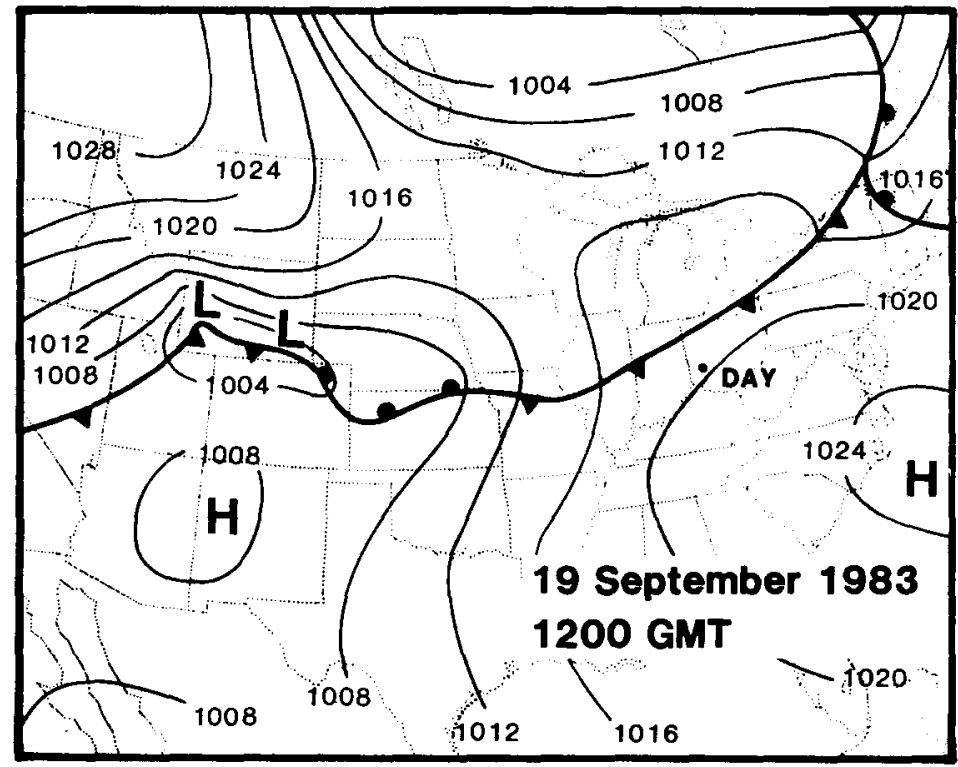

Fig. 5. Sea-level pressure analysis for 19 September 1983, 1200 UT.

temporal resolution combined. Arrows have been drawn at 6-h intervals. The four trajectories traversed almost identical paths until they diverged after $9 \mathrm{~h}(19$
September, $0300 \mathrm{UT}$ ). At the point of divergence. winds measured at the NWS station in Buffalo, NY, the nearest measurement site, were primarily respon- 


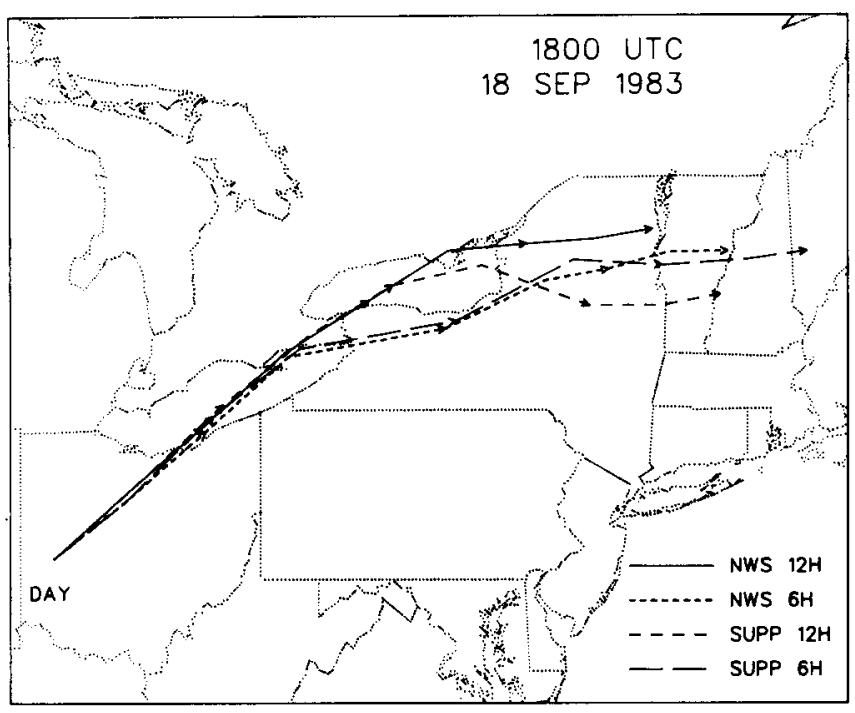

Fig. 6. Mixed layer trajectories originating at Dayton, $\mathrm{OH}$, at $1800 \mathrm{UT}$ on 18 September 1983. Arrows have been drawn at 6-h intervals.

sible for the calculated advection. The $12-\mathrm{h}$ resolution trajectories ('NWS 12HR' and 'SUPP 12HR') were assigned a $0300 \mathrm{UT}$ wind speed of $13.8 \mathrm{~m} \mathrm{~s}^{-1}$ by linear interpolation of 0000 and $1200 \mathrm{UT}$ measurements. The corresponding wind speed for the 6-h resolution trajectories ('NWS 6HR' and 'SUPP 6HR'), was $17.9 \mathrm{~m} \mathrm{~s}^{-1}$, obtained by linear interpolation of 0000 and $0600 \mathrm{UT}$ measurements.

The faster, more westerly track of the 6-h trajectories may be attributed to the stronger, more westerly wind measured at 0600 UT at Buffalo. This measurement proved critical in defining the transport speed for the 6-h trajectories. After $12 \mathrm{~h}$ of transport these trajectories were influenced primarily by winds measured at the cluster of supplemental rawinsonde stations in New York state. These trajectories traveled eastward at a greater speed than the 'NWS 12HR' trajectory. The 'NWS $6 \mathrm{HR}$ ' trajectory also traveled faster than the 'NWS $12 \mathrm{HR}$ ' trajectory because of the large $0600 \mathrm{UT}$ wind speed measured at Buffalo. After $24 \mathrm{~h}$ the 'NWS 12:HR' and 'SUPP 6HR' trajectories were separated by $225 \mathrm{~km}$. This case demonstrates the potential effects of a single additional measurement at an existing NWS station.

\section{Case 2: CAPTEX release no. 5 .}

The fifth CAPTEX tracer experiment, the first of two Sudbury, Ontario releases, was conducted from 0345 to 0645 UT on 26 October 1983. Surface features for $1200 \mathrm{UT}$ on 26 October, nearly $6 \mathrm{~h}$ after the release terminated, are shown in Fig. 7. A large highpressure system with a central axis extending from Utah to Texas covered most of the continental U.S. A cold front extended southward from Quebec into the central CAPTEX region. Surface winds behind the

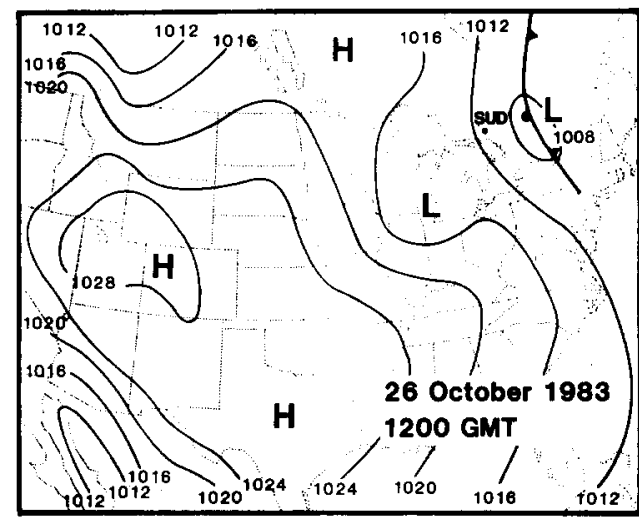

Fig. 7. Sea-level pressure analysis for 26 October 1983,1200 UT.

cold front were west-northwest during the $24 \mathrm{~h}$ following the tracer release, while the upper-level flow was northwesterly. Measurable precipitation occurred throughout the experimental region.

Mixed layer trajectories originating at Sudbury at $0600 \mathrm{UT}, 45 \mathrm{~min}$ before the end of the 3-h tracer release, are shown in Fig. 8 . In this case the sensitivity to spatial data resolution was striking. The trajectories calculated with NWS data only ('NWS 12HR' and 'NWS 6HR') traveled in a southeasterly direction for the first $12 \mathrm{~h}$, with an average speed of about $4 \mathrm{~m} \mathrm{~s}^{-1}$. They began to pick up speed as they moved southeasterly across Lake Ontario and into New York. The trajectories utilizing supplemental data behaved quite differently, particularly in the early stages. Initially they were directed toward the south-southeast at a speed of $16 \mathrm{~m} \mathrm{~s}^{-1}$, as measured by the supplemental 
CAPTEX 5

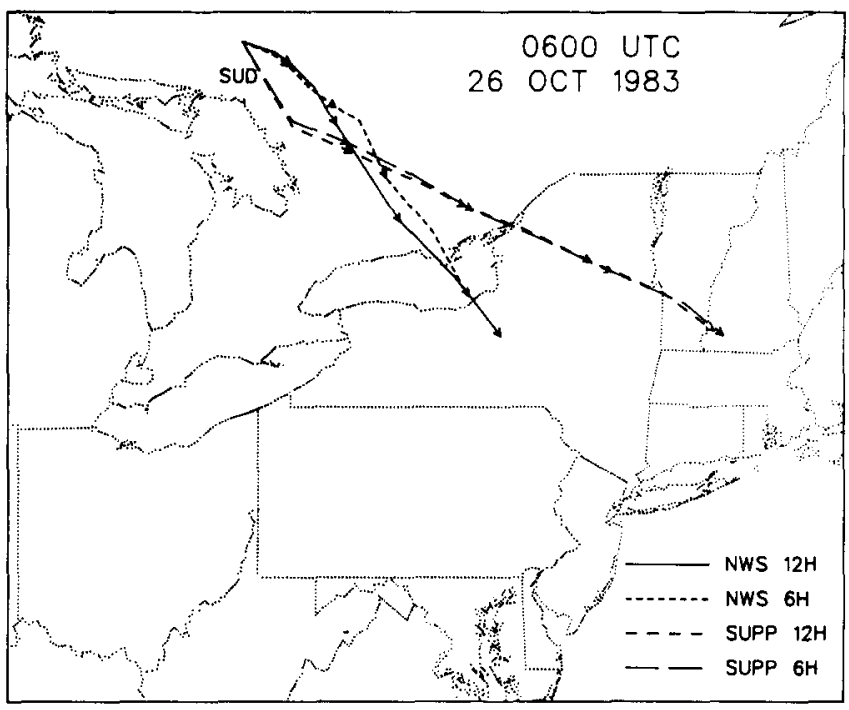

Fig. 8. Mixed layer trajectories originating at Sudbury, Ontario, at 0600 UT on 26 October 1983. Arrows have been drawn at 6-h intervals.

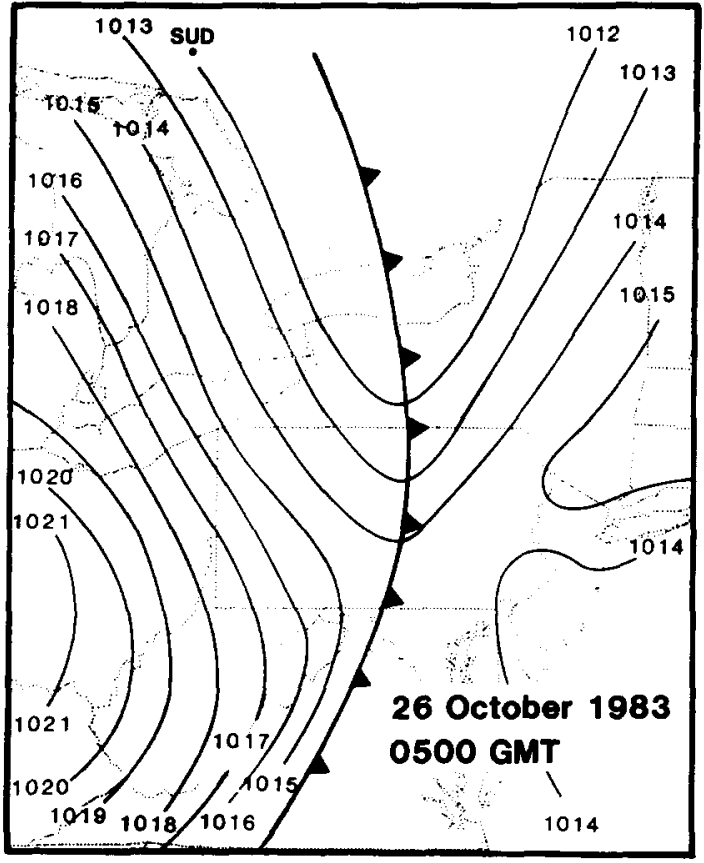

Fig. 9. Sea-level pressure analysis for 26 October 1983 , $0500 \mathrm{UT}$.

rawinsonde station located at the trajectory origin. After $3 \mathrm{~h}$ the trajectories backed toward the southeast and traveled at an average speed of about $5 \mathrm{~m} \mathrm{~s}^{-1}$. After $24 \mathrm{~h}$ they were located over southwestern New Hampshire. The difference in $24 \mathrm{~h}$ locations between the 'NWS 12HR' and 'SUPP 6HR' trajectories was $325 \mathrm{~km}$.

The increased sensitivity in the early stages of the trajectories may be understood by inspecting the surface map for $0500 \mathrm{UT}$ on 26 October, $1 \mathrm{~h}$ before the trajectory originated (Fig. 9). The origin was located about $100 \mathrm{~km}$ behind the cold front. The initial $(0600$ UT) wind for the NWS trajectories was obtained from measurements at surrounding NWS rawinsonde stations. These soundings, vertically averaged through the depth of the mixed layer, were spatially interpolated to the origin. Due to the proximity of Sudbury to the front, some of the winds used in the interpolation were measured ahead of the front. In contrast, the 'SUPP 12HR' and 'SUPP 6HR' trajectories utilized winds measured at the supplemental rawinsonde station located at the trajectory origin Thus the combination of interpolation in a frontal region and the location of a supplemental rawinsonde station at the origin resulted in a heightened sensitivity to data resolution. This case demonstrates the importance of specifying the initial transport wind accurately. Objective analyses of surface tracer measurements prepared by Haagenson et al. (1987) suggest that the trajectories utilizing supplemental data approximated the tracer transport quite well.

\section{SUMMARY AND CONCLUSIONS}

Rawinsonde data collected during the Cross Appalachian Tracer Experiment were used to evaluate the sensitivity of trajectory calculations to variations in input data resolution. Trajectories calculated using twice-daily NWS measurements were compared separately with trajectories based on data of enhanced spatial, temporal, and spatial and temporal resolution combined. Variable mixed layer, constant layer, and constant level trajectories were more sensitive to increases in spatial resolution than to increases in 
temporal resolution of rawinsonde measurements. Further sensitivity due to combined increases in both spatial and temporal data resolution was larger than that due to spatial resolution alone. It must be emphasized, however, that 'increased spatial resolution' refers to the inclusion of the supplemental rawinsonde stations shown in Fig. 1. Alternative placement of these stations may alter the trajectory calculations and influence the sensitivity results.

For mixed layer, 0-400-m layer, and 400-m level trajectories, sensitivity to combined increases in both spatial and temporal rawinsonde data resolution was saturated by the effects of spatial resolution alone. This saturation, presumably due to vertical wind shear effects, was not observed for trajectories calculated at higher levels and layers. This result has implications for the expected benefits of possible improvements to the current rawinsonde network. If the spatial resolution of the network were increased, trajectory uncertainties at all levels and layers would be reduced. Improving the temporal resolution of the spatially enhanced network would yield significant further improvement only for trajectories calculated at layers and levels above $400 \mathrm{~m}$.

This conclusion is consistent with our earlier assessment of wind interpolation errors during CAPTEX (Kahl and Samson, 1986). That analysis demonstrated that improvements in spatial resolution of rawinsonde measurements will increase mixed layer trajectory accuracy to a greater extent than will improvements in temporal resolution. While our previous work was designed to quantify trajectory errors, the present study examined trajectory sensitivity without specifically addressing errors. Caution must be used, therefore, in interpreting the results of this study as estimates of trajectory accuracy.

Case studies corresponding to two CAPTEX tracer releases were presented. These examples illustrated the potential effects of a single additional measurement at an existing NWS station (case 1), and the importance of specifying the initial transport wind accurately (case
2). Case 2 also provided evidence that spatial interpolation in the vicinity of a cold front introduced additional uncertainties into trajectory calculations.

The sensitivity results presented here are representative of the relatively quiescent meteorological conditions observed during CAPTEX. Further research is necessary to determine whether these findings may be generalized to other meteorological scenarios.

Acknowledgements - This work was supported by the Electric Power Research Institute under Contract RP1630-51. We thank Bill Kuo of the National Center for Atmospheric Research for providing the original version of the trajectory plotting software.

\section{REFERENCES}

Clarke J. F., Clark T. L., Ching J. K. S., Haagenson P. L., Husar R. B. and Patterson D. E. (1983) Assessment of model simulation of long-distance transport. Atmospheric Environment 17, 2449-2462.

Ferber G. J., Heffter J. L., Draxler R. R., Lagomarsino R. J., Thomas F. L., Dietz R. N. and Benkovitz C. M. (1986) Cross-Appalachian tracer experiment (CAPTEX '83) final report. NOAA Tech. Mem. ERL ARL-142, 60 pp.

Haagenson P. L., Kuo Y.-H. and Skumanich M. (1987) Tracer verification of trajectory models J. Clim. appl. Met. 26, 410-426.

Heffter J. L. (1980) Air Resources Laboratory Atmospheric Transport and Dispersion Model (ARL-ATAD). NOAA Tech. Mem. ERL ARL-81, Air Resources Laboratory, Silver Spring, MD, 24 pp.

Kahl J. D. and Samson P. J. (1986) Uncertainty in trajectory calculations due to low resolution meteorological data. $J$. Clim. appl. Met. 25, 1816-1831.

Kuo Y.-H., Skumanich M., Haagenson P. L. and Chang J. S. (1985) The accuracy of trajectory models as revealed by the observing system simulation experiments. Mon. Weath. Rev. 113, 1852-1867.

Walmsley J. L. and Mailhot J. (1983) On the numerical accuracy of trajectory models for long-range transport of atmospheric pollutants. Atmos. -Ocean 21, 14-39.

Warner T. T., Fizz R. R. and Seaman N. L. (1983) A comparison of two types of atmospheric transport models - use of observed winds versus dynamically predicted winds. J. Clim. appl. Met. 22, 394-406. 